\title{
The Research on the Ecological Environment Construction and Poverty Alleviation Development in "Three Rivers Parallel Flow Area" of Yunnan Province
}

\author{
Yongqian Li, Yerong $\mathrm{Li}^{*}$ \\ (Faculty of Economics and Management, Yunnan Agricultural University, XiaoKanDaDao Street, \\ Kunming City, Yunnan Province, P. R. China) \\ E-mail:13987162465@163.com; E-mail: leeyr1965@163.com
}

*Corresponding author

Keywords: Ecological Environment, Poverty Alleviation, three Rivers Parallel Flow Area, Yunnan Province

\begin{abstract}
In the process of the regional ecological environment construction in "Three Rivers Parallel Flow Area", the regional resources, the relationship between economy and environment should be taken into consideration. Based on market-oriented and serious comparison between opportunity and cost, we should change the resource-oriented development idea, ensure the sustainable development of economy and society, and realize win-win situation of ecological environment protection and economic and social development. With the implementation of the western development and the requirement of strengthening ecological environment, it is important to consistently implement and expand protection of forest construction along the Lancang River, Jinsha River, and $\mathrm{Nu}$ River, and combine environmental benefits, social benefits and economic benefits. To aim at regional poverty, we seek to coordinate economic, social, environmental resources which not only meet the needs of modern people and but also protect future generations, preserving the world natural heritage, and providing effective way for the sustainable development and ecological security for the downstream countries or regions.
\end{abstract}

\section{Introduction}

"Three Rivers Parallel Flow" district is located in the northwest of Chinese Yunnan province the Diqing Tibetan Autonomous Prefecture, Nujiang Lisu Autonomous Prefecture, the Lijiang Naxi Autonomous Prefecture administrative areas, by originated in the Qinghai-Tibet plateau of the Nujiang river, the Lancang river and Jinsha river, these are composed of the three great river parallel running areas. In reality, the "Three Rivers Parallel Flow Area" exists to solve the problem of residents' food and clothing, the extensive mode of production and the traditional way of life will continue on, which cause the further deterioration of the local ecological environment, the threat to biodiversity, the contradiction between population and resource environment. Data show that only the Jinsha river basin soil erosion area reached 4.7 square kilometers, soil loss among the top of the six major river basins in Yunnan province, accounting for $42.83 \%$ of the area of the basin, basin soil loss of 260 million tons per year. These poor counties of country priority aids in the "Three Rivers Parallel Flow Area", the poverty mainly shows for the county economy development lags behind, and the root cause is the slow development of industrial economy, the industrial development pattern rough, productive factors accumulation and continuous input low. The poverty counties are lack of competition ability of supporting industry, and economic scale expansion, the local finance income, urban and rural residents' income growth are weak. 


\section{Literature Review and Subject Analysis}

\subsection{Regional "resources -- economy -- environment" relationship}

The understanding of the relation between "resources - economy - environment" differs, some people think they are contradictory, but some think that they are consistent. Facing resource depletion and environment pollution caused by the industrial revolution, people pay more attention to the rational development and utilization of resources in their economic development. According to the economic and environmental resources as well as economic thought, with the reflections on traditional behavior and concept, the sustainable concept coming into being, which would make it attainable for the resource saving, environmental amity and ecological civilization in resources, economy and, environment. Adam Smith (1776) is the founder of political economy, who proposed that the growth of population should be in proportion with living resources so as to maintain the harmonious development of human beings and natural environment. The aim of the sustainable development is to seek for the overall progress of society. The essence of the development is to improve human living quality, raise the level of human health, create a social environment that safeguards equality, freedom, education, and free of violence. Therefore, Sustainable development is not only the economic development, but also the overall progress in the field of social and cultural development of a society as a whole.

Internationally, work about sustainable development in economics is "Beyond Growth, Sustainable Development of Economics" (1996) by Herman·E·Daly, American famous ecological economists, said: "the whole idea of sustainable development is within the growing scale of economic subsystem, and would not beyond scope of support of ecosystem." British classical economists William.Petty once said, "Labor is the father of wealth, and land is the mother of wealth". Environmental bearing capacity is a kind of artificial constraints, and its size is concerned with factors such as environmental standards, environmental capacity, living standard and way of human economic activities, all of which plays a role of restrictions on economic activity. Resources carrying capacity is a natural endowment, the size of which depends on the abundance of the resources in the ecosystem, human demand for resources and factors such as the mode of resource utilization. It supports effect of the economic activity. Within the scope of the bearing capacity, the environment has certain self-adjustment ability, but the ability is limited (referred to as "Environmental Threshold"). Once human activities surpass the environmental threshold, it can lead to irreversible damage to the environment, known as environmental degradation.

\subsection{Environmental Kuznets curve}

In the mid of $1960 \mathrm{~s}$, Simon'Kuznets put forward a hypothesis: in the process of economic development, income disparity increases with economic growth at the beginning, and then the differences began to shrink. The logic meaning of this curve shows that before things get better, the worse may have to experience a process. The practice has proved that in many countries there is the inverted "U" shaped relationship between economic growth and environmental quality. And it is shown in figure 1-1 and 1-2. 

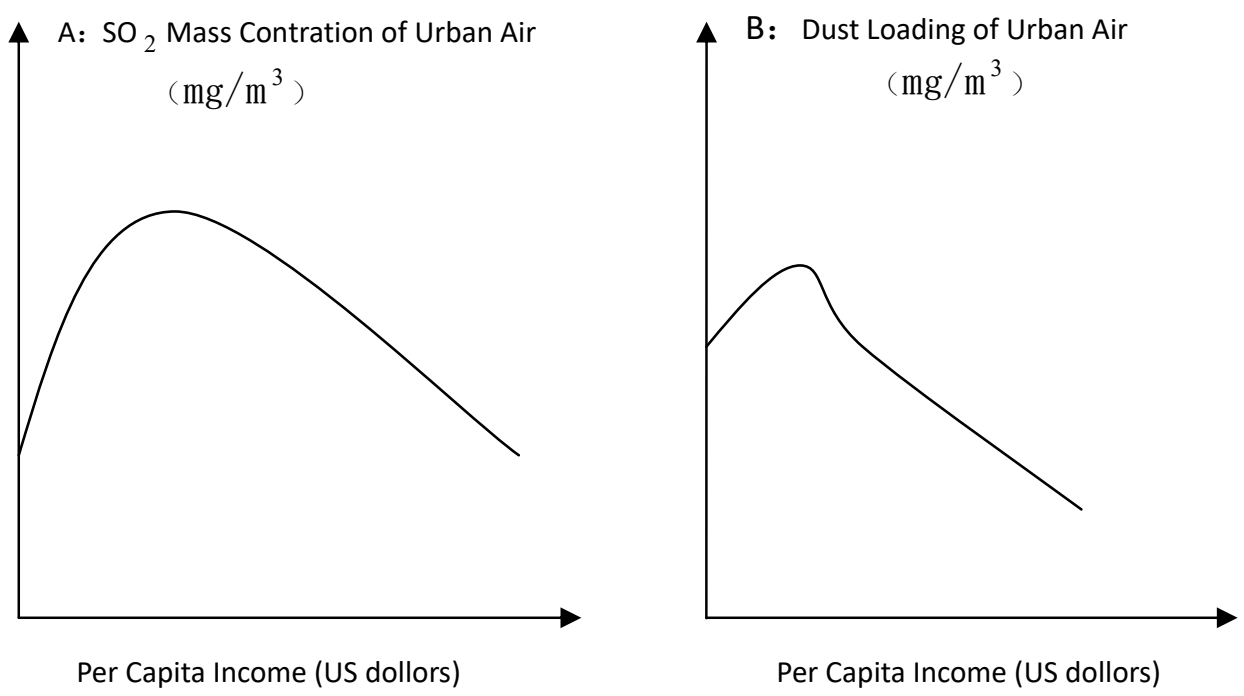

Figure 1 Per Capita Income and Environmental Status

(Data Source: Pan Jiahua, the economic analysis on the sustainable development way)

Environmental quality and economic development of the inverted " $U$ " type curve is the environmental Kuznets curve. The policy implication of Environmental Kuznets curve is that in the course of development, especially in the take-off stage of industrialization, a country or region will inevitably suffer a certain degree of environmental degradation till the per capita income reached a certain level, and economic development is conducive to the improvement of environmental quality.

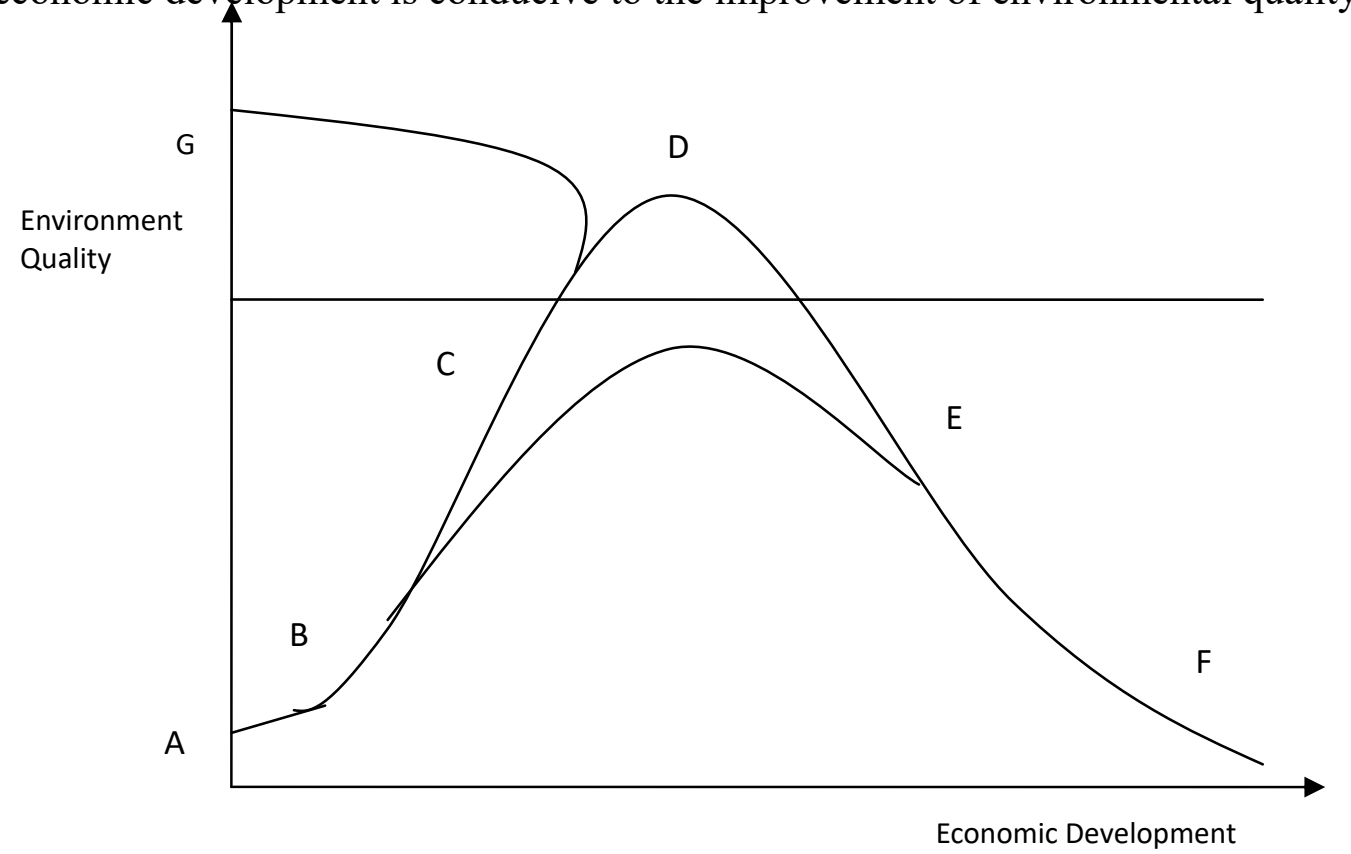

Figure 2 The change of the economic development and environmental quality

As an agricultural country, China feeds 22 percent of the world's population with only 7 percent of the world's arable land. But the increasing population and the decrease in cultivated land worsened agricultural ecosystem. To guarantee the high yield and stable yield of the crops, the input of pesticide chemical fertilizer increased rapidly in the agricultural production. A British expert assessed that if China does not have chemical pesticide to control pests, China would have 70 percent of crop loss. According to statistics, China's the usual occurrence area of perennial plant diseases and insect pests is about 6 billion mu, but due to the use of pesticides, the average annual loss has been saved more than 20 billion kilograms of grain, over 10 billion kilograms of vegetables, over 3 billion kilograms of fruit, and over 1 billion kilograms of cotton, reducing about 50 billion 
yuan of the direct economic loss.

\subsection{The farmers' income and ecological protection in the "Three Rivers Parallel Flow Area"}

Farmers in the "Three Rivers Parallel Flow Area" mainly live in the scattered villages of mountainous area. Traffic inconvenience and lack of coal sources make the establishment of electricity power plant difficult because household drinking water, heating, lighting and building materials depend on firewood. As the main source of forest consumption, the wood is the main cause for the decline of forest resources in the three counties with annual consumption accounting for $65.94 \%$ of the total material. The increase of farmer's income and the ecological protection should be taken into account in the selection of poverty alleviation industry in the area of Three Parallel Rivers. First of all, the selection of the poverty alleviation industry should be on the premise of ecological protection, because its goal is to increase the incomes of the poor, and to meet the demand of daily necessities, or to meet the needs of more requirements of life. The development of any industry is inseparable from the use of natural resources. Natural resources are limited, and divided into renewable and nonrenewable resources. Once the nonrenewable resources exhausted, it could not regenerate in a long time.

\subsection{The problem analysis of preventing Resource Curse occurrence in the "Three Rivers Parallel Flow Areas"}

Resource Curse is an economic theory, and it refers to economic and social problems related to mineral resources. Abundant natural resources may be curse rather than a blessing, because the in the economic development in the most natural resource-rich countries grow more slowly than countries that resources are scarce. Economists attribute it to a deteriorating term of trade, the Dutch disease or lack of human capital investment, which is mainly due to too much dependence on the relatively rich resources. In order to prevent the occurrence of "Resource Curse", local governments should focus on the development of other industries, industry cultivation should be on the premise of ecological protection, the development of the industry should be based on good ecological environment, and the industry should be contributed to the benign interaction with ecological protection.

\section{Conclusion}

First, a comprehensive understanding of the relationship of unity and opposites between environment and economy, research to achieve economic development and the ecological environment protection and improvement in "Three Rivers Parallel Flow Area", promote each other, the way of common development.

Second, a comprehensive understanding of economic activities on the ecological environment of positive influence and negative influence, economic activities on the regional poverty alleviation work in accordance with the laws of ecology, with minimal environmental costs to realize the regional poverty alleviation work and the way of rapid economic growth in the "Three Rivers Parallel Flow Area".

Third, comprehensive understanding of the promotion and restriction function about environmental construction to the anti-poverty work of economic construction in the poverty-stricken areas of "Three Rivers Parallel Flow Area", study the ecological environment construction to conform to the requirements of the economic law, with the minimum labor consumption ways to obtain the best environmental benefits and economic benefits, achieve the goal of areas out of poverty.

\section{Acknowledgements}

This paper is an achievement of fund project supported by National Planning

Office of Philosophy and Social Science named Study on Rural Chronic Poverty in West Minority Areas Based on Ecological Security Perspective. 
Project Number: 17BJY130

\section{References}

[1] National Bureau of Statistics. China's Rural Poverty Monitoring Reports (2009-2011) [M].Beijing: China Statistics Press, 2012.

[2] Yunnan Provincial Bureau of Statistics. Yunnan Statistical Yearbook 2011 [M].Beijing: China Statics Press, 2012.

[3] Jiahua Pan: the Economic Analysis on the Sustainable Development Way [M]. Beijing: the press of Renmin University of China, 1997. pp. 94-91.

[4] Wenhua Li. The Comprehensive Treatment of Farmland and Rural Ecological Problems [M].Beijing: China Agriculture Press, 2008, 8.

[5] Sangui Wang. Poverty and Economic Development Policy [M].Beijing: Rural Literature Publishing House, 2004.

[6] Zuhui Huang. The Study of the Problem of Rural Poverty and Anti-poverty in China [M]. Hanzhou: Zhejiang University Press, 2008.

[7] Thomas. The Quality of Growth [M].Beijing: China Financial Economic Publishing House, 2001.

[8] Herman'E·Daly. Beyond the Growth, the Economics of Sustainable Development [M].Shanghai Translation Publishing House, 2001, p. 38.

[9] Theodore Schulz. The Theory of Human Capital Investment [M]. Beijing: Beijing Institute of Economic Press, 1990, p.57.

[10] Markus Pasche. Technical progress , structural change, and the environmental Kuznets curve [ J]. Ecological Economics, 2002, 42(2). pp. 381-389. 